http://jmscr.igmpublication.org/home/

ISSN (e)-2347-176x ISSN (p) 2455-0450

crossref DOI: https://dx.doi.org/10.18535/jmscr/v7i7.71

$\underline{\text { Research Article }}$

\title{
To study the changes in platelets both qualitative and quantitative in all pregnant and compare with nonpregnant women of same age group
}

\author{
Authors \\ Dr Shalini Jain ${ }^{1}$ (Asst. Prof.), Dr Jayant Doshi ${ }^{2 *}$ (Demonstrator) \\ Dr Pawan Bhambani ${ }^{3}$ (Asst. Prof.) \\ ${ }^{1,3}$ Dept. of Pathology, Index Medical College Hospital \& Research Centre, Indore \\ ${ }^{2}$ Dept. of Pathology, Mahatma Gandhi Memorial Medical College \& M. Y. Hospital, Indore \\ *Corresponding Author \\ Dr Jayant Doshi
}

Demonstrator, Dept. of Pathology, Mahatma Gandhi Memorial Medical College \& M. Y. Hospital, Indore,

MP, India

\begin{abstract}
Background \& Method: The study was carried out in Pathology of Index Medical College Hospital and Research Center, Indore. It is a cross sectional study. 400 consecutive blood samples of pregnant women's as study group and 400 consecutive blood samples of non-pregnant women's as control group, were included in the study.

Result: One-Way ANOVA test was used. F value $=1.27$, P value $=0.282$, Not Significant. The F value obtained was 1.27 with a $P$ value of $>0.05$, which is statistically not significant. Thus, platelet values in all the three groups is comparable. As the ANOVA value was found to be non-significant.

Significant difference was seen between the pairs first trimester - second trimester; and second trimester third trimester, while non-significant difference was seen between first trimester - third trimester pair.

Conclusion: In our study we conclude that White blood cells and neutrophils were progressively increased whereas platelets were decreased in pregnant women compared to non-pregnant women as pregnancy advanced.

Study Designed: Observational Study.

Keywords: Platelets, Pregnant, Quality \& Quantitative.
\end{abstract}

\section{Introduction}

Pregnancy put extreme a stress on the hematological system. It therefore is very essential that understanding of the physiological changes is obligatory in order to interpret any need for therapeutic intervention. ${ }^{1}$

Hematological parameters reflect these adaptive changes which become very important baseline parameters to evaluate all impending complications during pregnancy.
Any abnormality from the normal baseline in pregnancy of various parameters like Hemoglobin reflect anemia, red blood cells indices reflect type of anemia, morphological changes in $\mathrm{RBC}$ and WBC also reflect type of anemia and infection, platelet count will reflect impending eclampsia in pregnancy. $^{2}$

It is proposed that present study will bring out various hematological changes in pregnant women with special reference to the neutrophils. The 
deviation in parameter may be used as surrogate markers for impending pathophysiolgical changes in mother and fetus. ${ }^{3}$

Platelets have limited circulation lifetimes, have limited mitophagy (a major mechanism for the removal of damaged mitochondria), and do not produce new mitochondria. Though platelets have few mitochondria per cell, established techniques for isolation of a large number of platelets provide a sample with a relatively high mitochondrial content for respirometric analysis. ${ }^{4}$

\section{Material \& Method}

The study was carried out in Pathology of Index Medical College Hospital and Research Center, Indore. Pregnant women attending Outpatient department of OBG, It is a cross sectional study. 400 consecutive blood samples of pregnant women's as study group and 400 consecutive blood samples of non-pregnant women's as control group, were included in the study.

\section{Inclusion Criteria}

1. Women's of 20 to 40 years attending antenatal clinic of Index Medical College Hospital and Research Center, Indore was selected.

2. Women's giving urine pregnancy test positive or are positive for live fetus in ultrasonography was included in our study as study group and who are negative for the same was taken as control group.

\section{Exclusion Criteria}

Patient with

- Bleeding disorders

- Splenomegaly

- Connective tissue disease such as systemic lupus erythematosus

- Hypertension

- Human immunodeficiency virus (HIV)

- Hepatitis B infection

- Women on non-steroidal antiinflammatory drugs such as aspirin were also excluded.
Study was done in 24 months starting from Oct. 2013 to Sep 2015.

\section{Statistical Analysis}

Data were analyzed using SPSS (20.0). The descriptive data are presented herein as means \pm standard deviation (SD). The differences were considered statistically significant when the $P$ value obtained $<0.05$.

\section{Results}

One-Way ANOVA test was used. F value $=1.27$, $P$ value $=0.282$, Not Significant

The $\mathrm{F}$ value obtained was 1.27 with a $\mathrm{P}$ value of > 0.05 , which is statistically not significant. Thus, platelet values in all the three groups is comparable. As the ANOVA value was found to be non-significant.

Table No. 01 Comparison of Mean Platelet between the groups

$(\mathrm{N}=400)$

\begin{tabular}{|l|c|c|c|}
\hline Parameter & $\begin{array}{c}\text { First } \\
\text { Trimester } \\
(\mathbf{n}=\mathbf{1 5 6})\end{array}$ & $\begin{array}{c}\text { Second } \\
\text { Trimester } \\
(\mathbf{n}=\mathbf{1 5 5})\end{array}$ & $\begin{array}{c}\text { Third } \\
\text { Trimester } \\
(\mathbf{n}=\mathbf{8 9})\end{array}$ \\
\cline { 2 - 4 } & $($ Mean \pm SD) & Mean \pm SD $)$ & $($ Mean \pm SD $)$ \\
\hline Platelet & $2.02 \pm 0.69$ & $1.92 \pm 0.70$ & $2.05 \pm 0.69$ \\
\hline
\end{tabular}

\section{Comparison of Mean Neutrophil between the groups}

One-Way ANOVA test was used. $\mathrm{F}$ value = $16.09, \mathrm{P}$ value $=0.000$, Significant

The $F$ value obtained was 16.09 with a $P$ value of $<0.05$, which is statistically significant. Thus, neutrophil values in all the three groups are statistically different.

Table No. 02 Comparison of Mean Neutrophil between the groups

$(\mathrm{N}=400)$

\begin{tabular}{|c|c|c|c|}
\hline Parameter & $\begin{array}{c}\text { First } \\
\text { Trimester } \\
(\mathbf{n}=\mathbf{1 5 6})\end{array}$ & $\begin{array}{c}\text { Second } \\
\text { Trimester } \\
(\mathbf{n}=\mathbf{1 5 5})\end{array}$ & $\begin{array}{c}\text { Third Trimester } \\
(\mathbf{n}=\mathbf{8 9})\end{array}$ \\
\cline { 2 - 4 } & $($ Mean \pm SD) & $($ Mean \pm SD) & $($ Mean \pm SD) \\
\hline Neutrophil & $70.79 \pm 7.18$ & $75.69 \pm 7.22$ & $72.44 \pm 9.22$ \\
\hline
\end{tabular}

Significant difference was seen between the pairs first trimester - second trimester; and second trimester - third trimester, while non-significant difference was seen between first trimester - third trimester pair. 


\section{Discussion}

The platelet count often drops slightly, with an accepted lower limit of normal range in pregnancy (mild thrombocytopenia), while white cell count increases due to an increase in circulating neutrophils (neutrophilia). Changes occur in the coagulation system, with increased procoagulant activity, decreased natural anticoagulant activity, and decreased fibrinolysis, resulting in a prothrombotic state. ${ }^{5}$

A study on physiological changes in hematological parameters during pregnancy. They found that pregnancy is a state characterized by many physiological hematological changes, which may appear to be pathological in the non-pregnant state. The review highlights most of these changes along with the scientific basis for the same, as per the current knowledge, with a special reference to the red blood and white blood cells, platelets and hemostatic profile. In their review article entitled physiological changes in hematological parameters, they reported leukocytosis, neutrophilia, lymphocytopenia and thrompocytopenia during pregnancy. ${ }^{6}$

Platelet count was progressively decreased in pregnant women compared to non-pregnant women as the pregnancy advanced. Significant decreases in platelet count of pregnant women compared to non-pregnant women $(\mathrm{P}$ value $<0.05)$ in agreement with study reported that: although platelet counts remain in the normal pregnant range in most women during uncomplicated pregnancies (Matthews et al., 1990). ${ }^{7}$ mean platelet counts of pregnant women may be slightly lower than in healthy non pregnant women (Verdy et al., 1997). ${ }^{8}$

\section{Conclusion}

In our study we conclude that White blood cells and neutrophils were progressively increased whereas platelets were decreased in pregnant women compared to non-pregnant women as pregnancy advanced.

\section{References}

1. Roberts J.M., August P.A., Bakris G., Barton J.R., Bernstein I.M., Druzin M. et al. (2013) Hypertension in pregnancy. Report of the American College of Obstetricians and Gynecologists' Task Force on Hypertension in Pregnancy Obstet. Gynecol. 122, 1122-1131

2. Tran HA."Biochemical tests in pregnancy", Australian Prescriber 2005;(28): 98- 101.

3. Swanepoel A.C. and Pretorius E. (2015) Ultrastructural analysis of platelets during three phases of pregnancy: a qualitative and quantitative investigation. Hematology 20, 39-47

4. Goonewardene M, Shehata M. Anemia in pregnancy. Best Practice and Research clinic Obstetric Gynecology 2011.

5. Connors JM. Hematologic Disorders in Pregnancy. Hematology/Oncology Clinics of North America 2011;25:13-4.

6. Chandra S, AK, Mishra S, Amzarul M, Vaish AK (2012): Physiological Changes in Hematological Parameters During Pregnancy. Indian Journal of Hematology and Blood Transfusion 2012; 28:144-6.

7. Matthews JH, Benjamin S, Gill DS, Smith NA. Pregnancyassociated thrombocytopenia: definition, incidence and natural history, Acta Haematol1990;84:24.

8. Verdy E, Bessous V, and Dreyfus M. Longitudinal analysis of platelet count and volume in normal pregnancy. Thromb Haemost1997; 77:806. 